\title{
Workplace Adjustments for Autistic Employees: What is 'Reasonable'?
}

\author{
Stephanie Petty ${ }^{1}\left[\right.$ [D $\cdot$ Lydia Tunstall ${ }^{2} \cdot$ Hannah Richardson ${ }^{2} \cdot$ Niamh Eccles $^{2}$ \\ Accepted: 15 December 2021 / Published online: 12 January 2022 \\ (c) The Author(s), under exclusive licence to Springer Science+Business Media, LLC, part of Springer Nature 2022
}

\begin{abstract}
Autistic adults are inadequately supported in the workplace. This study sought a definition of 'reasonable' and explored facilitators and barriers to employers making reasonable adjustments. 98 employers and employees across a UK city completed a survey; $15 \%$ identified as being autistic. Qualitative data were analysed using framework analysis. Reasonable adjustments were defined as having a positive impact on autistic employees' wellbeing and work outputs without being detrimental to non-autistic employees or the organisation; they were low cost and easily implemented. Recommendations were for autism awareness training, low-stimulus work spaces, clear instructions and flexible working hours. A definition of reasonable is added to the literature, with suggestions of where to invest support efforts. Recommendations mostly apply to the education sector.
\end{abstract}

Keywords Employment $\cdot$ Autism spectrum disorders $\cdot$ Qualitative research $\cdot$ Equality $\cdot$ Training

Autism Spectrum Disorder (ASD, referred to throughout as autism; American Psychiatric Association, 2013) is a lifelong condition, with widely variable individual expressions and support needs, which go beyond early identification and intervention (Taylor et al., 2012; Whelpley et al., 2020). Notably, better understanding is needed of ways to achieve meaningful employment for autistic adults (Pellicano et al., 2014). In the UK, only a fifth of autistic adults are in some kind of employment, in comparison with four fifths of the general population and half of the disabled population (Office for National Statistics, 2021). Further to unemployment, autistic adults tend to be underemployed, being in part-time work, experiencing frequent job switching or being employed in roles that require minimal expertise (Baldwin et al., 2014; Frank et al., 2018; Scott et al., 2015). These difficulties gaining and maintaining employment are not in keeping with the skillset, education or desire to work of autistic adults (López \& Keenan, 2014; Scott et al., 2015; Taylor \& Seltzer, 2011).

Stephanie Petty

s.petty@yorksj.ac.uk

1 School of Education, Language and Psychology, York St John University, York YO31 7EX, UK

2 Department of Psychology, University of York, York YO10 5DD, UK
Some of the widespread positive implications of successful employment include financial independence, improved quality of life and improved wellbeing (Hendricks, 2010; Solomon, 2020). Conversely, unemployment can negatively impact mental and physical health in a wide range of ways, including contributing to stress, emotional distress and financial strain, which ease when employment is gained (Wanberg, 2012). For autistic employees, job dissatisfaction and working in a non-preferred role interacts negatively with wellbeing, productivity and motivation (Hedley et al., 2019; Scott et al., 2015). Insufficient support provided in the workplace not only negatively impacts upon autistic individuals but means that employers are missing out on valuable workplace contributions from neurodiverse employees: positive contributions are suggested to include innovative solution-finding, boosted productivity with good attention to detail and concentration, reliability and workplace morale (National Autistic Society, 2011; Patton, 2019). Currently, there is little research that explores this optimum fit for both employee and employer (Bölte, 2021). However, employers are required to understand their employees' needs and provide tailored workplace adjustments to enable autistic employees to do their job successfully (Equality \& Human Rights Commission, 2010).

Whilst recognising the heterogeneous and widely variable experiences of autistic adults (Whelpley et al., 2020), there are commonly-reported employment difficulties. For 
example, recruitment practices rely heavily on social interaction and expectations of common etiquette; busy and distracting environments can be overly challenging for sensory processing difficulties; frequent miscommunications are caused by unwritten rules of the workplace including holding social roles at work; and difficulties arise in responding flexibly to unpredictable demands (Bury et al., 2020; Gal et al., 2015; National Autistic Society, 2019; Sarrett, 2017). Many autistic employees report negative attitudes and a lack of understanding from their colleagues, with half reporting bullying or harassment at work (National Autistic Society, 2016a). Many autistic employees say they are not receiving adequate support to overcome these barriers (Buckley et al., 2020; López \& Keenan, 2014).

In an attempt to address the autism employment gap, the UK government introduced the Autism Act 2009 and the Equality Act 2010. These laws intend to make the workplace accessible to all, by requiring employers to implement "reasonable adjustments" in order to remove barriers to employment caused by disability. These aims are shared by international legislation, such as the Americans with Disabilities Act, where "reasonable accommodations" are required by employers to enable a person with a disability to work with the same ease and privilege as any other employee. However, currently, employers are without detailed guidance of how to enact these laws, with particular misunderstanding of what constitutes a reasonable adjustment (Roberts et al., 2011). Provisional examples of reasonable adjustments have been provided by autistic people, their families and service providers. These include environmental modifications, such as reducing noise, adjusting lighting or allowing employees to wear headphones, which have been deemed to have the biggest impact on successful employment (Black et al., 2019; Hedley et al., 2018). Modifications to communication, including providing written instructions, reduced social interaction and the provision of flexible working hours have been described as beneficial (Black et al., 2019; Hayward et al., 2019). Support and advice from understanding coworkers, facilitated through autism workplace training, has also been suggested to foster positive workplace relationships (Black et al., 2019; Hedley et al., 2018). Guides make these recommendations accessible to employers (National Autistic Society, 2016b). Unfortunately though, the available guidance is not reaching everyday practice (Lee \& Carter, 2012).

Despite having some understanding of autism, employers report low confidence in supporting autistic employees in real world practice and do not know what resources to draw upon (Buckley et al., 2020; Scott et al., 2015). Workplace adjustments vary considerably, with the majority of employees receiving no adjustments (Lindsay et al., 2019). A failure to provide adjustments is described by autistic employees as an important barrier to them gaining and maintaining employment (López \& Keenan, 2014).

Therefore, despite legal obligations to provide workplace support, and available guidance suggesting ways to implement support for autistic employees, reasonable adjustments continue to be unavailable for all. Importantly, a foundational definition of "reasonable", which is fit for workplaces, is missing (Bowman, 2020; Lindsay et al., 2019; Scott et al., 2017).

This study asked employees and employers working across a range of industries to define "reasonable" in the context of making reasonable adjustments for autistic employees. It should be noted that both autistic and nonautistic contributed. In addition, this study asked employees when reasonable adjustments can and cannot be made, to better understand the barriers to providing workplace support. The study aimed to provide direction to employers and contribute to more consistent delivery of support for autistic employees.

Identity-first language, "autistic employee" was chosen with consideration of available guidance (Fletcher-Watson \& Happé, 2019) and in consultation with an autistic expertby-experience, who had a diagnosis of autism, had relevant experience of research methods and who held a student mentor job role; they were paid for their time.

\section{Methods}

\section{Design}

This study implemented a survey. An online-hosted questionnaire collected demographic, quantitative and qualitative data about current experiences of the workplace.

\section{Participants}

A total 58 organisations in a city in the north of the UK were approached because they committed to improving their employees' wellbeing through recognised schemes, including Disability Confident (a government-led employment scheme offering disability training, advice and self-assessments for businesses) and Investors in People (a not-forprofit project offering assessment, advice and accreditation in supporting the workforce). Sampling did not exclude any industry sector. Those approached included education, health and social care, retail, transport and charitable sectors, as well as others. All selected organisations were contacted with an invitation to share the questionnaire with all employees. There were no exclusion criteria; all employees and employers were invited to take part. This sought multiple workplace contexts. 


\section{Data Collection}

Data was collected through November and December 2020. The questionnaire was developed in consultation with an autistic expert-by-experience, an occupational therapist and a clinical psychologist working in a specialist autism diagnostic and support service delivering NHS and private contracts in the north of the UK. The survey was revised with one autistic adult and five neuro-typical adults without intellectual disability to reduce ambiguity and ensure the content was pertinent. The online platform enabled participation during a period of mixed homeworking and office-working.

Demographic questions recorded participant age, gender identity, ethnicity, organisation size and sector, whether participants had recruitment responsibilities, whether participants had a diagnosis of ASD, whether they had autistic colleagues, whether they had autistic family members or friends and whether they had completed training relating to autism in the workplace.

After providing demographic information, participants were asked to define "reasonable" in the context of employers making reasonable adjustments to support their employees who have autism. Participants were then asked to indicate from a multiple choice list the adjustments they had observed in the workplace for autistic employees: these were compiled from the research literature by an occupational therapist. The list included: clarifying job expectations (e.g. providing clear rules and guidelines to follow); providing additional training; using written and visual instructions as well as verbal instructions; ensuring that the working day is well-structured to suit the needs of the employee (e.g. using detailed weekly timetables); offering regular performance reviews; offering feedback and/or additional mentoring; providing reassurance in stressful situations; making environment modifications (e.g. finding ways to reduce noise or brightness); providing autism awareness training for employees; explaining upcoming changes (e.g. support employees when meeting new people); providing additional support through the recruitment process (e.g. providing questions prior to the interview); offering flexible working hours or travel arrangements; none of the above. Participants were then presented with the same list again and were asked to indicate the adjustments that would be feasible to implement in their workplace.

The following open-ended questions sought qualitative data: participants were asked to discuss the most beneficial adjustments to implement in the workplace for autistic employees with reasons why, and discuss adjustments that would be the most difficult to implement and why; they were asked how they would know whether an autistic colleague was well supported; and were asked what resources, if any, they were aware of when supporting autistic colleagues, such as schemes, grants or charities. Finally, participants were asked whether there had been any notable impacts on their responses due to COVID-19.

The median time taken to complete the survey was $15 \mathrm{~min}$.

This dataset formed part of a larger quantitative data set, including data on understanding and confidence in the workplace and freelisting data.

\section{Data Analysis}

Framework analysis was applied to the qualitative data (Ritchie \& Spencer, 1994). The approach offers a transparent and structured process for analysing the views of a large sample, and when there are specific questions being asked (Gale et al., 2013). Analysis consists of five systematic and interconnected stages: for each of the six open-ended questions in turn, responses were read repeatedly (stage 1 familiarisation); relevant phrases were highlighted and given a numerical value to form codes that stayed true to participant responses and formed a coding framework (stage 2 constructing the framework); the preliminary framework was applied to a subset of transcripts and refined through multiple iterations in discussion with the full research group; codes were applied to all original transcripts (stage 3: indexing and sorting); coded data were entered into a matrix to summarise participant responses for each code with illustrative quotes (stage 4: charting); similar codes were combined to develop themes that represented meanings across participants; these were reviewed against original transcripts (stage 5: mapping and interpretation). All stages of the analysis were documented to create an audit trail. No new codes were generated from the final 10 transcripts for any question, therefore saturation was assumed.

This process was repeated to create a framework for the subset of data provided by autistic employees; this allowed for comment on the views of this subsample of participants and areas of agreement or additional insight provided.

A random $10 \%$ sample of the transcripts was coded by an independent researcher. The percentage agreement was $82 \%$ for a total of 94 quotes, meaning both reviewers selected the same code on these occasions. Cohen's kappa was used as an estimate of inter-rater reliability, which controls for the error of multiple raters agreeing by chance; this showed agreement at $\mathrm{k}=0.33$, indicating "fair agreement", to be improved. Discussion was used to resolve disagreements and clarify coding decisions.

\section{Results}

\section{Participant Demographics}

The survey was completed by 98 employees. The sample predominantly worked in the education sector $(83 \%)$; other 
sectors included social care (3\%), healthcare $(3 \%)$, retail $(1 \%)$ and transport (1\%). Thirty-two percent of respondents were responsible for recruitment in their workplace; there was a spread of employed roles across the organisational hierarchy. The majority of participants were White British (83\%), similar to population prevalence estimates in England and Wales, and the majority identified as female (70\%), which is higher than the general population (Office for National Statistics, 2012). There was a spread of participants across age groups, most were aged 45-54 (29\%). Fifteen percent of participants disclosed that they had a diagnosis of autism. Thirty-eight percent said they had colleagues with a diagnosis of autism. The majority had personal experience of autism, having autistic family members or friends (85\%). The majority of participants had not completed any formal training related to autism in the workplace (70\%).

\section{Observed Workplace Adjustments}

From a multiple choice list of possible adjustments for autistic employees, the most frequently observed were: clarifying job expectations (observed by $41 \%$ ) and offering flexible working hours or flexible travel arrangements (41\%). Least frequently observed was employers providing additional support through the recruitment process (13\%) and 17\% of respondents said they had observed none of the listed adjustments in their workplace. Most respondents indicated that each of the listed adjustments was feasible to implement, ranging from 63 to $83 \%$. There was a marked difference between the number of adjustments observed and those thought to be practical and feasible to implement. Providing autism awareness training for employees (83\%), clarifying job expectations $(76 \%)$ and providing reassurance in stressful situations (76\%) were most frequently selected as being practical and feasible to implement. No respondents thought that no adjustments were feasible to implement.

\section{Framework Analysis}

To indicate the frequency of participant views, "most" refers to more than $50 \%$ of participants; "many" refers to $30-49 \%$ of participants; "some" refers to 11-29\% and "few" refers to less than $10 \%$ of participants. Table 1 shows the main themes.

\section{Definition of "Reasonable"}

Having a Positive Impact on the Employee's Wellbeing and Work Outputs Most respondents defined reasonable adjustments as having a positive impact both on employee wellbeing and on their ability to work. Reasonable adjustments were modifications to the working context "that can be done to better support the individual to achieve in their post, complete the tasks and responsibilities allocated to them" (P48). They also respond directly to the "barriers" faced by autistic employees (P24). When reasonable adjustments are implemented, employees should be able to work well, to the same standard as their colleagues, on a "level playing field" (P70). They should be comfortable and confident in their employed position.

Without Negative Impact for the Organisation Most respondents also considered the employer when defining "reasonable": adjustments should not cause "undue hardship" (P76) or "financially penalise" (P57) the organisation in any way. Participants said a careful balance needed to be reached between employee and organisational needs, with the reasonable adjustments being those which had the great-

Table 1 Framework showing themes from qualitative questionnaire responses

\begin{tabular}{ll}
\hline Survey question & Themes \\
\hline Definition of "reasonable" & $\begin{array}{l}\text { Having a positive impact on the employee's wellbeing and work outputs } \\
\text { Being without negative impact for the organisation } \\
\text { Being available for all employees } \\
\text { Individually designed }\end{array}$ \\
Build understanding of autism through training and frequent discussions \\
Beneficial adjustments for the workplace & $\begin{array}{l}\text { Modify the environment } \\
\text { Offer flexible support in immediate response to anxiety and overwhelm } \\
\text { Are practically easy and cost-free }\end{array}$ \\
Troublesome adjustments for the workplace & $\begin{array}{l}\text { Relate to unchangeable and uncontrollable aspects of work } \\
\text { Use limited resources } \\
\text { Introduce unfairness amongst colleagues }\end{array}$ \\
Ways of knowing that an autistic colleague is well-supported & $\begin{array}{l}\text { Respecting colleague privacy } \\
\text { Hosting regular reviews }\end{array}$ \\
Resources for supporting autistic colleagues & There is little awareness of resources \\
& Known resources include financial support and charities
\end{tabular}


est positive effect on autistic employees but the smallest negative impact upon the organisation.

Available for All Employees Some respondents said that reasonable adjustments should bring equality to the workplace, so that any adjustments made allow "everyone to work at their best" (P89) and should ensure that "everyone was treated fairly" (P96), with reasonable adjustments being available to every employee.

Individually Designed Some participants said reasonable adjustments must be individualised, with the definition of reasonable varying with each person. A personal definition would be agreed through open conversations between employers and employees. One autistic employee said, "I don't expect every system to be as comfortable for me; I do expect flexibility and understanding when that shows" (P79).

\section{Beneficial Adjustments for the Workplace}

Build Understanding of Autism Autism awareness training was most frequently identified as a beneficial adjustment to implement in the workplace, with the main reason being that this would enable the entire workforce to support autistic colleagues: "if everyone understands the issue, everyone can help" (P38). An autistic employee explained that a lack of understanding amongst their colleagues contributed to behaviour perceived as bullying. In addition to training, regular discussions between employees and employers about strengths, needs and possible support options were recommended.

Modify the Environment Some respondents said that changes to the work environment are particularly beneficial; this was because stressful aspects of the environment "are constant and can make everything else more difficult for an autistic person - they're going to struggle to understand e.g. visual instructions if the only thing they can really focus on is e.g. the flickering lighting" (P80). Thus, physical adjustments were said to have a "knock-on impact" (P13), or a cumulative impact, on other aspects of work. Examples of environmental adjustments included reducing noise and altering lighting.

\section{Offer Flexible Support in Response to Anxiety and Over-} whelm Some respondents said that providing responsive and tailored support was the most beneficial workplace adjustment; reassurance and allowing for flexible working hours were said to be "important when employees are experiencing anxiety or stress" (P35) and required a timely response. They also required "a good understanding of the individual and an ability to identify when they are in a situ- ation they find stressful (which is sometimes not obvious to others and they may not communicate they feel stressed)" (P21).

Select Practically Easy Support Options The practical implementation of adjustments was considered by few participants who said the most beneficial adjustments were those that could be easily implemented and implemented "at no extra cost" (P37). Examples included clarifying job expectations, providing written instructions, environmental modifications and providing autism awareness training.

\section{Troublesome Adjustments for the Workplace}

Unchangeable and Uncontrollable Aspects of Work The most difficult adjustments to implement concerned unalterable aspects of work, such as daily routines of the whole workplace and "unpredictable... unexpected ... and new" work demands (P67) that override a planned work schedule. Also mentioned as difficult to alter were routines in jobs that rely on consistent schedules and naturally "busy and loud" environments (P27).

Limited Resources Some respondents expressed concerns about the availability of staff, finances, time and resources to initiate adjustments: "Many of the adjustments require that a manager or existing member of staff take on the extra responsibility" (P8). Concerns were notably of overstretched staff with particular implication for being able to offer mentoring or regular reviews.

Maintaining Fairness for All Colleagues Few respondents expressed concern about the implementation of adjustments that would impact upon all colleagues, particularly those which altered a shared environment or recruitment practices: "Giving interview questions in advance - I think colleagues might think this was unfair on other candidates unless we gave them to everyone" (P17). In agreement with previous questionnaire responses, where adjustments were made, they needed to be available to all.

\section{Ways of Knowing that an Autistic Colleague is Well-Supported}

Employee Privacy On the whole, respondents expressed confidence in their ability to recognise an ill-supported colleague; many identified indicators of workplace wellbeing that could help with identifying colleagues who required more support, including a colleague being "well-integrated, able to do their job to their full capacity, comfortable in their environment and able to do their job without feeling isolated" (P60). Contrastingly, some participants said they would not know whether a colleague was well-supported: 
"I don't think we would - we might be aware that a colleague has autism, but it would be hard to know they were well supported as we wouldn't be privy to any adjustments" (P57). Respondents said that not all colleagues feel comfortable in disclosing their needs, thus knowing if they are wellsupported becomes difficult.

Regular Reviews Many respondents emphasised the need for formal procedures to routinely check on employee wellbeing. "I think the only way to be sure, would be to ask the colleague with autism. Not just once of course, but as part of a regular review process" (P55).

\section{Resources for Supporting Autistic Colleagues}

Most respondents were unaware of any resources that could be used to support autistic colleagues. This included respondents who had indicated a diagnosis of autism: "As a person who has grown up with autism, I still know of none" (P77). Some respondents were able to provide a range of resources that can be used when supporting autistic colleagues, including financial support, charities and organisations, locally and nationally: examples included the National Autistic Society, the Access to Work scheme (UK government funding for personally tailored adaptations or support interventions that aim to remove work-related barriers), Autistica (a national charity, which funds and shapes research to better understand autistic needs) and Living Autism (an independent organisation offering advice and signposting to autism support services).

\section{Impacts of Working From Home}

With increased homeworking, meaning employees working from their homes, throughout the 2019 COVID-19 pandemic in the UK, many participants acknowledged both positive and negative impacts for autistic colleagues. Participants stated that constant unpredictable and sudden changes caused stress and anxiety for autistic employees: "the whole situation being fluid and not knowing when it will end" (P81). Being able to regulate the homeworking environment worked well for some autistic colleagues, regulating social interactions and sensory demands, helping them to be "more focused and relaxed" (P84). In contrast, others expressed concern for colleagues feeling isolated; also with difficulties caused by online communication. One respondent who had indicated a diagnosis of autism said "in regard to homeworking, staff with autism will need much more support, more than other staff, much more uncertainty etc. and they may suffer more in silence and not feel able to say anything or ask questions to help them feel better" (P64).

\section{Discussion}

This study collated workplace experiences of autistic and non-autistic employees in the UK. Findings provide a definition of "reasonable" in the context of employer obligations to make reasonable adjustments for their autistic employees (Autism Act 2009; Equality \& Human Rights Commission, 2010). Employees in this study thought that reasonable adjustments were practical and feasible to implement by employers. Considerations are discussed for when offering workplace support, to ensure that barriers are avoided and efforts made will have the most beneficial impact. The important context of these findings is the underemployment of autistic adults, where support guidance is available (Black et al., 2019; Hayward et al., 2019; Hedley et al., 2018) but not routinely implemented (Buckley et al., 2020; Scott et al., 2015).

This study concludes with the following definition: reasonable adjustments will enable autistic employees to be well at work, with maximised work performance, and will level the playing field so that being autistic is not a disadvantage - in balance with - adjustments being low cost, easily delivered and available to all employees. Adjustments to choose are those that best meet both sides of this balance simultaneously.

With this definition in mind, there is likely to be a repertoire of achievable adjustments within any organisation. For autistic employees, options to modify the environment by altering lighting or reduce noise to reduce sensory processing demands, to work flexible hours where possible, to receive clear job expectations, clear instructions and to be offered reassurance in stressful situations were priority considerations. These findings corroborate previous literature (Black et al., 2019; Hedley et al., 2018). Some employers have considered flexible working to be easy to implement, alongside the provision of quiet spaces (Buckley et al., 2020). The most commonly observed adjustment by employees in this study was flexible working hours or travel arrangements. In addition, possible environmental modifications are vast (Simpson, 2016). With these modifications in mind, hiring of autistic employees is not perceived by some employers to incur any additional costs (Scott et al., 2017).

Making an organisation's adjustments accessible to all employees was also recommended: this approach can reduce perceptions of unfairness and can contribute to an inclusive workplace environment (Flower et al., 2019; Patton, 2019). This finding is consistent with the concept of universal design (Burgstahler \& Russo-Gleicher, 2015), whereby workplaces can be designed to be useable by all employees, informed by the needs of autistic employees, to create an inclusive environment that recognises variability 
in employees' needs. This is in contrast to making changes in the workplace only in response to the disclosure of a specific disability.

Most participants in this study had autistic colleagues or autistic family members or friends, and some were autistic, thus the recommendations are likely informed by a personal understanding of autism. Respondents advocated for a tailored approach to making workplace adjustments through discussion with each individual employee. Guidance for employers therefore offers a starting list of recommended adjustments, but advocates against a "one size fits all" approach (Hagner \& Cooney, 2005; National Autistic Society, 2019; Remington \& Pellicano, 2018). Consistent with previous literature, discussion of meaningful adjustments must be with the employee and be individually tailored (Hagner \& Cooney, 2005; Remington \& Pellicano, 2018). It will be important to take time to consider the most impactful adjustments for each employee to improve their workplace achievement and wellbeing.

It is also important to note, however, the barriers of truly responsive and tailored support because of overstretched staff, and the toll of time-consuming or continuous efforts, such as regular reviews, and unalterable aspects of work. Similar concerns have been expressed by employers in previous studies (Buckley et al., 2020; Jacob et al., 2015; Waisman-Nitzan et al., 2019). This could explain why, despite participants agreeing that an individualised approach should be taken, this is not always translated into working practice (López \& Keenan, 2014). Here, "reasonable adjustments" are defined as those that can practically be implemented within the constraints of the organisation.

As a priority solution, autism awareness training was suggested. Employees in this study thought that providing autism awareness training for employees was the most practical and feasible reasonable adjustment for employers to offer. A lack of understanding in the workplace is a significant barrier for autistic employees (Lindsay et al., 2019; López \& Keenan, 2014). Workplace training has the potential to increase the confidence and job performance of autistic employees (Dreaver et al., 2020). It also facilitates the sharing of unique difficulties faced by autistic colleagues (Bowman, 2020; Hendricks, 2010; Scott et al., 2017). The majority of participants in this study had neither completed any training relating to autism in the workplace, nor were they aware of any available resources for workplace support (López \& Keenan, 2014). Enhanced investment into making resources and training available and accessible to all workplaces is needed (Buckley et al., 2020; Remington \& Pellicano, 2018). Additionally, autism training needs to be revised to include positive contributions that autistic employees make. Studies have highlighted the workplace benefits of characteristics common in autistic individuals, including creativity, attention to detail and low absenteeism
(Hendricks, 2010; Scott et al., 2017). Ensuring that workplaces are aware of autism, specific struggles and positive contributions, and adjustments that can be implemented without excessive difficulty or unfairness may mitigate employers' reluctance to hire autistic employees (Scott et al., 2017).

For future research, the development of an assessment tool to capture the main workplace difficulties, consider a short-list of possible adjustments and enable employers and employees to work together to identify reasonable adjustments, may facilitate these recommendations being put into working practice (Bölte, 2021). Indication of need from such a tool could prompt the provision of review spaces, or prompt discussion about wellbeing within existing meeting structures, such as supervision, line management or appraisal. A needs-led approach would minimise the time invested in regular reviews if not required for all employees, and may support autistic employees to communicate their difficulties (Buckley et al., 2020; Remington \& Pellicano, 2018).

Finally, this study offers comment on the impacts of COVID-19 on autistic employees. Positive impacts of homeworking included employees being able to control social and sensory demands of their working, though the majority of respondents had concerns of isolation and exaggerated difficulty articulating support needs. Previous research has recognised the negative impacts of uncertainty and disruption to routines (Cassidy et al., 2020; Oomen et al., 2021). The difficulties highlighted here draw attention to the need for additional support and tailored adjustments to be put into place to support autistic employees whilst working from home. There is little research to inform how reasonable adjustments can be implemented remotely, or how current information and guidance can be tailored to adapt to homeworking. This warrants further study.

\section{Limitations}

The education sector was best represented in this study. Organisations were also part of employee wellbeing schemes. It is possible that these organisations were more familiar with both autism and the provision of employee support, hence they opted to participate, which illustrates some of the idiographic characteristics or exceptions of these workplaces (Anderson et al., 2017; Patton, 2019). Future data collection might consider ways to reach smaller organisations and reach employees that do not work routinely at a computer to diversify the sample. Future research may also consider ways of objectively assessing the provision of adjustments, as well as markers of workplace satisfaction and performance to expand these self-report data. 
Acknowledgments This research received no specific grant from any funding agency in the public, commercial, or not for-profit sectors. We would like to acknowledge and thank The Retreat York for their review of the study.

Authors Contributions All authors contributed to the study conception and design. Material preparation, data collection and analysis were performed by Lydia Tunstall, Hannah Richardson and Niamh Eccles. The first draft of the manuscript was written by Stephanie Petty and all authors commented on previous versions of the manuscript. All authors read and approved the final manuscript.

Funding The authors did not receive support from any organization for the submitted work.

\section{Declarations}

Conflict of interest The authors have no relevant financial or non-financial interests to disclose.

Ethical Approval The study was approved by the University of York ethics committee and was performed in accordance with the ethical standards as laid down in the 1964 Declaration of Helsinki and its later amendments. All participants volunteered to take part and gave written informed consent. Any information that could identify an individual or organisation was removed from the data. Each participant was given a unique code (e.g., P1). All participants were provided with a debrief information sheet containing support signposting.

\section{References}

American Psychiatric Association. (2013). Diagnostic and Statistical Manual of Mental Disorders (DSM-5). American Psychiatric Publishing.

Anderson, A. H., Stephenson, J., \& Carter, M. (2017). A systematic literature review of the experiences and supports of students with autism spectrum disorder in post-secondary education. Research in Autism Spectrum Disorders, 39, 33-53.

Baldwin, S., Costley, D., \& Warren, A. (2014). Employment activities and experiences of adults with high-functioning autism and Asperger's disorder. Journal of Autism and Developmental Disorders, 44(10), 2440-2449. https://doi.org/10.1007/s10803-014-2112-z

Black, M. H., Mahdi, S., Milbourn, B., Thompson, C., D’Angelo, A., Ström, E., \& Bölte, S. (2019). Perspectives of key stakeholders on employment of autistic adults across the United States, Australia, and Sweden. Autism Research, 12(11), 1648-1662. https://doi. org/10.1002/aur.2167

Bölte, S. (2021). "We believe in good jobs, fair jobs, dignifying jobs that give you a good sense of identity": Career and job guidance counseling in autism. Autism, 25(4), 857-861. https://doi.org/10. $1177 / 1362361321990325$

Bowman, A. D. (2020). What we know about employers' perspectives on successfully integrating adults with Autism Spectrum Disorders in the workplace. International Journal of Psychiatry Research, 3(1), 1-4.

Buckley, E., Pellicano, E., \& Remington, A. (2020). "The real thing I struggle with is other people's perceptions": The experiences of autistic performing arts professionals and attitudes of performing arts employers in the UK. Journal of Autism and Developmental Disorders, 51(1), 45-59. https://doi.org/10.1007/ s10803-020-04517-0
Burgstahler, S., \& Russo-Gleicher, R. J. (2015). Applying universal design to address the needs of postsecondary students on the autism spectrum. Journal of Postsecondary Education and Disability, 28(2), 199-212.

Bury, S. M., Flower, R. L., Zulla, R., Nicholas, D. B., \& Hedley, D. (2020). Workplace social challenges experienced by employees on the autism spectrum: An international exploratory study examining employee and supervisor perspectives. Journal of Autism and Developmental Disorders. https://doi.org/10.1007/ s10803-020-04662-6

Cassidy, S. A., Nicolaidis, C., Davies, B., Rosa, S. D. R., Eisenman, D., Onaiwu, M. G., \& Waisman, T. C. (2020). An expert discussion on autism in the COVID-19 pandemic. Autism in Adulthood, 2(2), 106-117. https://doi.org/10.1089/aut.2020.29013.sjc

Dreaver, J., Thompson, C., Girdler, S., Adolfsson, M., Black, M. H., \& Falkmer, M. (2020). Success factors enabling employment for adults on the autism spectrum from employers' perspective. Journal of Autism and Developmental Disorders, 50(5), 1657-1667. https://doi.org/10.1007/s10803-019-03923-3

Equality and Human Rights Commission. (2010). Equality Act 2010 Employment Statutory Code of Practice. HMSO.

Fletcher-Watson, S., \& Happé, F. (2019). Autism: A new introduction to psychological theory and current debate. Routledge.

Flower, R. L., Hedley, D., Spoor, J. R., \& Dissanayake, C. (2019). An alternative pathway to employment for autistic jobseekers: A case study of a training and assessment program targeted to autistic job candidates. Journal of Vocational Education \& Training, 71(3), 407-428. https://doi.org/10.1080/13636820. 2019.1636846

Frank, F., Jablotschkin, M., Arthen, T., Riedel, A., Fangmeier, T., \& Hölzel, L. P. (2018). Education and employment status of adults with autism spectrum disorders in Germany - a cross-sectionalsurvey. BMC Psychiatry, 18(1), 1-10. https://doi.org/10.1186/ s12888-018-1645-7

Gal, E., Landes, E., \& Katz, N. (2015). Work performance skills in adults with and without high functioning autism spectrum disorders (HFASD). Research in Autism Spectrum Disorders, 10, 71-77. https://doi.org/10.1016/j.rasd.2014.10.011

Gale, N. K., Heath, G., Cameron, E., Rashid, S., \& Redwood, S. (2013). Using the framework method for the analysis of qualitative data in multi-disciplinary health research. BMC Medical Research Methodology, 13(1), 1-8. https://doi.org/10.1186/ 1471-2288-13-117

Hagner, D., \& Cooney, B. F. (2005). "I do that for everybody": Supervising employees with autism. Focus on Autism and Other Developmental Disabilities, 20(2), 91-97. https://doi.org/10.1177/ 10883576050200020501

Hayward, S. M., McVilly, K. R., \& Stokes, M. A. (2019). Autism and employment: What works. Research in Autism Spectrum Disorders, 60, 48-58. https://doi.org/10.1016/j.rasd.2019.01.006

Hedley, D., Cai, R., Uljarevic, M., Wilmot, M., Spoor, J. R., Richdale, A., \& Dissanayake, C. (2018). Transition to work: Perspectives from the autism spectrum. Autism, 22(5), 528-541. https://doi. org/10.1177/1362361316687697

Hedley, D., Uljarević, M., Bury, S. M., \& Dissanayake, C. (2019). Predictors of mental health and well-being in employed adults with autism spectrum disorder at 12-month follow-up. Autism Research, 12(3), 482-494.

Hendricks, D. (2010). Employment and adults with autism spectrum disorders: Challenges and strategies for success. Journal of Vocational Rehabilitation, 32(2), 125-134. https://doi.org/10.3233/ JVR-2010-0502

Jacob, A., Scott, M., Falkmer, M., \& Falkmer, T. (2015). The costs and benefits of employing an adult with autism spectrum disorder: A systematic review. PLoS ONE, 10(10), e0139896. https://doi.org/ 10.1371/journal.pone.0139896 
Lee, G. K., \& Carter, E. W. (2012). Preparing transition-age students with high-functioning autism spectrum disorders for meaningful work. Psychology in the Schools, 49(10), 988-1000.

Lindsay, S., Cagliostro, E., Leck, J., Shen, W., \& Stinson, J. (2019). Employers' perspectives of including young people with disabilities in the workforce, disability disclosure and providing accommodations. Journal of Vocational Rehabilitation, 50(2), 141-156. https://doi.org/10.3233/JVR-180996

López, B., \& Keenan, L. (2014). Barriers to employment in autism: Future challenges to implementing the Adult Autism Strategy. Autism Research Network. Retrieved June 11, 2021, from http://www.autismrpphub.org/sites/default/files/articles/emplo yment_report.pdf.

National Autistic Society (2011). Untapped Talent. Retrieved June 11, 2021, from https://www.3dnovations.co.uk/pdf/Untapped_Talen t_-_English.pdf.

National Autistic Society (2016b). Employing autistic people - a guide for employers. Retrieved June 11, 2021, from https://www.autism. org.uk/advice-and-guidance/topics/employment/employing-autis tic-people/employers.

National Autistic Society (2016a). The autism employment gap. Retrieved June 11, 2021, from https://www.basw.co.uk/system/ files/resources/basw_53224-4_0.pdf.

National Autistic Society (2019). The Autism Act, 10 years on: a report from the all parliamentary group on autism on understanding, services and support for autistic people and their families in England. Retrieved June 11, 2021, from https://pearsfoundation. org.uk/wp-content/uploads/2019/09/APPGA-Autism-Act-Inqui ry-Report.pdf.

Office for National Statistics (2012). 2011 Census: Population Estimates for the United Kingdom, March 2011. Retrieved June 11, 2021, from https://www.ons.gov.uk/peoplepopulationandcommun ity/populationandmigration/populationestimates/bulletins/2011c ensuspopulationestimatesfortheunitedkingdom/2012-12-17.

Office for National Statistics (2021). Outcomes for disabled people in the UK: 2020. Retrieved June 11, 2021, from https://www.ons. gov.uk/peoplepopulationandcommunity/healthandsocialcare/disab ility/articles/outcomesfordisabledpeopleintheuk/2020.

Oomen, D., Nijhof, A. D., \& Wiersema, J. R. (2021). The psychological impact of the COVID-19 pandemic on adults with autism: A survey study across three countries. Molecular Autism, 12(1), 1-21. https://doi.org/10.1186/s13229-021-00424-y

Patton, E. (2019). Autism, attributions and accommodations: Overcoming barriers and integrating a neurodiverse workforce. Personnel Review, 48(4), 915-934. https://doi.org/10.1108/ PR-04-2018-0116

Pellicano, E., Dinsmore, A., \& Charman, T. (2014). What should autism research focus upon? Community views and priorities from the United Kingdom. Autism, 18(7), 756-770. https://doi.org/10. $1177 / 1362361314529627$

Remington, A. M., \& Pellicano, E. (2018). Sometimes you just need someone to take a chance on you': An internship programme for autistic graduates at Deutsche Bank, UK. Journal of Management and Organization. https://doi.org/10.1017/jmo.2018.66
Ritchie, J., \& Spencer, L. (1994). Qualitative data analysis for applied policy research. In A. Bryman \& R. G. Burgess (Eds.), Analyzing qualitative data (pp. 173-194). Routledge.

Roberts, R., Beadle-Brown, J., \& Youell, D. (2011). Promoting social inclusion for children and adults on the autism spectrum - reflections on policy and practice. Tizard Learning Disability Review, 6(4), 45-52. https://doi.org/10.1108/13595471111172840

Sarrett, J. (2017). Interviews, disclosures, and misperceptions: autistic adults' perspectives on employment related challenges. Disability Studies Quarterly. https://doi.org/10.18061/dsq.v37i2.5524

Scott, M., Falkmer, M., Girdler, S., \& Falkmer, T. (2015). Viewpoints on factors for successful employment for adults with autism spectrum disorder. PLoS ONE, 10(10), e0139281. https://doi.org/10. 1371/journal.pone.0139281

Scott, M., Jacob, A., Hendrie, D., Parsons, R., Girdler, S., Falkmer, T., \& Falkmer, M. (2017). Employers' perception of the costs and the benefits of hiring individuals with autism spectrum disorder in open employment in Australia. PLoS ONE, 12(5), e0177607. https://doi.org/10.1371/journal.pone.0177607

Simpson, S. (2016). Checklist for autism-friendly environments. Retrieved June 11, 2021, from https://www.nice.org.uk/guidance/ cg142/resources/endorsed-resource-checklist-forautismfriendlyenvironments-2016-2665557037.

Solomon, C. (2020). Autism and employment: Implications for employers and adults with ASD. Journal of Autism and Developmental Disorders, 50(11), 4209-4217. https://doi.org/10.1007/ s10803-020-04537-w

Taylor, J. L., McPheeters, M. L., Sathe, N. A., Dove, D., VeenstraVanderWeele, J., \& Warren, Z. (2012). A systematic review of vocational interventions for young adults with autism spectrum disorders. Paediatrics, 130(3), 531-538. https://doi.org/10.1542/ peds.2012-0682

Taylor, J. L., \& Seltzer, M. M. (2011). Employment and post-secondary educational activities for young adults with autism spectrum disorders during the transition to adulthood. Journal of Autism and Developmental Disorders, 41(5), 566-574. https://doi.org/10. 1007/s10803-010-1070-3

Waisman-Nitzan, M., Gal, E., \& Schreuer, N. (2019). Employers' perspectives regarding reasonable accommodations for employees with Autism Spectrum Disorder. Journal of Management and Organization, 25(4), 481-498. https://doi.org/10.1017/jmo.2018. 59

Wanberg, C. R. (2012). The individual experience of unemployment. Annual Review of Psychology, 63, 369-396. https://doi.org/10. 1146/annurev-psych-120710-100500

Whelpley, C. E., Banks, G. C., Bochantin, J. E., \& Sandoval, R. (2020). Tensions on the spectrum: An inductive investigation of employee and manager experiences of autism. Journal of Business and Psychology, 36(2), 283-297. https://doi.org/10.1007/ s10869-019-09676-1

Publisher's Note Springer Nature remains neutral with regard to jurisdictional claims in published maps and institutional affiliations. 